\title{
Design and Evaluation of a Novel Gas Formation-Based Multiple-Unit Gastro-Retentive Floating Drug Delivery System for Quetiapine Fumarate
}

\author{
Vinay Kumar Katakam*, Sunil Reddy, Pavan Kumar Panakanti and \\ Madhusudan Rao Yamsani \\ University College of Pharmaceutical Sciences, Kakatiya University, Warangal, -506009 (A.P), India
}

*For correspondence: Email: yamsani123@gmail.com, vinaykatakam@yahoo.co.in; Tel: +91-870-2570543

Received: 6 March 2013

Revised accepted: 4 February 2014

\begin{abstract}
Purpose: To develop a gastro-retentive formulation of quetiapine fumarate in the form of floating minitablets.

Methods: The system consisted of core units prepared by direct compression process, which were coated with three successive layers, namely, an inner seal coat, effervescent layer and an outer polymeric layer of polymethacrylates.

Results: Mini-tablets coated with Eudragit RS $30 D$ (5, 7.5 and $10 \%$ ) released $\leq 85 \%$ of the drug after $12 \mathrm{~h}$, while those coated with Eudragit $R L 30 D$ (5, 7.5 and $10 \%$ ) released $\geq 85 \%$ drug within the same period. Drug release kinetic studies showed that drug diffusion fitted best to zero order and Higuchi models, indicating that drug release was anomalous non-Fickian transport. In vivo gastric residence time results indicate that the units remained in the stomach for about $6 h(n=3)$. There was no significant change in dissolution profiles before and after storage at $40^{\circ} \mathrm{C}$ and $75 \% \mathrm{RH}$ for 6 months. Conclusion: The developed floating mini-tablets of quetiapine fumarate exhibit prolonged release for $\geq 12 \mathrm{~h}$, and thus may improve bioavailability and minimize fluctuations in plasma drug concentrations.

Keywords: Mini-tablets; Floating delivery system; Effervescence, Polymeric membrane, Controlled release, Quetiapine fumarate

Tropical Journal of Pharmaceutical Research is indexed by Science Citation Index (SciSearch), Scopus, International Pharmaceutical Abstract, Chemical Abstracts, Embase, Index Copernicus, EBSCO, African Index Medicus, JournalSeek, Journal Citation Reports/Science Edition, Directory of Open Access Journals (DOAJ), African Journal Online, Bioline International, Open-J-Gate and Pharmacy Abstracts
\end{abstract}

\section{INTRODUCTION}

Multiple-unit floating polymeric drug delivery systems such as floating mini tablets offer advantages of retaining the dosage form in the upper part of GIT for prolonged period and thereby releasing the drug in a controlled manner. Such floating devices show more reproducible release profiles over fortuitous (allor-nothing emptying) nature or dose-dumping phenomenon associated with single-unit system [1]. They decrease inter subject variability in absorption and minimize the possibility of dose dumping by uniform distribution within the gastric content and provide longer duration of action [2].

Quetiapine fumarate (QF) is a typical antipsychotic agent, widely used for schizophrenia, anxiety, unipolar and bipolar disorder management [3-5]. The main site for absorption for QF is stomach as it exhibits very high solubility in gastric $\mathrm{pH}$ which falls drastically in intestinal $\mathrm{pH}$. Thus, it would be more beneficial to retain QF in the stomach $(\mathrm{pH} 1-3)$ for prolonged duration to achieve maximum absorption and bioavailability. The biological half- 
life and bioavailability of QF is $6 \mathrm{~h}$ and $9 \%$, respectively [6]. The drug shows hepatic metabolism and renal excretion.

QF shows $\mathrm{pH}$ dependent solubility, i.e., highly soluble in acidic $\mathrm{pH}$ and slightly soluble in basic $\mathrm{pH}$. As its solubility decreases with increase in $\mathrm{pH}$, it would be more beneficial to retain the drug in stomach (acidic environment) for prolonged duration so as to achieve maximum absorption and bioavailability So gastroretentive drug delivery system is desirable to prolong the residence time of the dosage form in the stomach or upper gastrointestinal tract until the drug is completely released from the system hence, quetiapine fumarate was chosen as the drug candidate for the present work. The system consisted of drug-containing core minitablets coated with seal coat, effervescent layer and gas entrapped polymeric membrane, respectively. The objective of this study was to develop a new approach using floating mini-tablets filled into capsules based on gas formation technique.

\section{EXPERIMENTAL}

\section{Materials}

Quetiapine Fumarate and Microcrystalline cellulose (MCC) (Avicel PH102) were gift sample from AET laboratories Pvt. Ltd, Hyderabad, India. Methocel K4M CR (4000 mPa.s), Methocel K15M CR (15 000 mPa.s) and Methocel K100M LV CR (100 $000 \mathrm{mPa} . \mathrm{s})$ were received as gift samples from Colorcon Asia Pvt Ltd (Goa, India). Sodium bicarbonate (Merk, India) was used as an effervescent agent with HPMC (Methocel E15LV), plasticized with polyethylene glycol 6000 (PEG 6000 Merck, India) as a binder. The gas entrapped polymeric membrane used was polymethacrylates (Eudragit RL and RS, Rohm Pharma, Germany) plasticized with triethyl citrate (Himedia), a water soluble plasticizer. All other reagents were of analytical grade.

\section{Physical characterization of the final lubricated blend}

Physical properties of the final blend such as bulk density, tapped density, compressibility index, Hausner ratio and the angle of repose were determined using standard procedures. Tapped density was determined by using a tapped density tester (Electrolab, Model ETB1020).

\section{Preparation of core mini-tablets}

Core mini tablets were prepared with direct compression process according to the formula in
Table 1. Quetiapine fumarate, microcrystalline cellulose, HPMC (K100LV) and ethylcellulose, were weighed and sifted through 420 microns and mixed well. Magnesium stearate was weighed and sifted through 420 microns then added to the above blend and mixed well in polybag. Final blend was compressed into minitablets using $3.50 \mathrm{~mm}$ size round concave punches and corresponding dies on a 16-station rotary compression machine (Riddhi, India).

Table 1: Composition of core mini-tablets

\begin{tabular}{|c|c|c|c|c|}
\hline Ingredient & Quantity & mg/caps & & \\
\hline $\begin{array}{l}\text { Stage-A (dry } \\
\text { mix and } \\
\text { lubrication) }\end{array}$ & $A$ & B & $\mathrm{C}$ & $\mathrm{D}$ \\
\hline $\begin{array}{l}\text { Quetiapine } \\
\text { Fumarate }\end{array}$ & 230.442 & 230.442 & 230.442 & 230.442 \\
\hline $\begin{array}{l}\text { Methocel K100 } \\
\text { LV }\end{array}$ & 50.00 & 75.00 & 25.00 & 75.00 \\
\hline $\begin{array}{l}\text { Ethyl Cellulose } \\
\text { (7cps) }\end{array}$ & 50.00 & 25.00 & 75.00 & 25.00 \\
\hline Avicel (PH 101) & 42.558 & 42.558 & 42.558 & 42.558 \\
\hline $\begin{array}{l}\text { Magnesium } \\
\text { Stearate }\end{array}$ & 5.00 & 5.00 & 5.00 & 5.00 \\
\hline Aerosil & 2.00 & 2.00 & 2.00 & 2.00 \\
\hline Total weight & 380.00 & 380.00 & 380.00 & 380.00 \\
\hline $\begin{array}{l}\text { Mini tablet weight } \\
(\mathrm{mg}) 3.5 \mathrm{~mm} \\
\text { tablets }\end{array}$ & 38 & 38 & 38 & 38 \\
\hline
\end{tabular}

\section{Coating of the core mini-tablets}

The core units were coated with three successive layers; first with seal coat (HPMC), followed by effervescent substance (sodium bicarbonate) as an inner effervescent layer and polymethacrylate (Eudragit RS30D, RL30D, and RS30D: RL30D $1: 3, \quad 3: 1$ and $1: 1$ ) as an outer gas-entrapped polymeric membrane.

\section{Seal coating}

Hypromellose (20 g, 5 cP, Methocel 8 E5 - LV Premium) was dissolved in $161 \mathrm{~g}$ of iso propyl alcohol. To this, $69 \mathrm{~g}$ purified water was added and mixed for $60 \mathrm{~min}$. The dispersion was made to contain $8 \% \mathrm{w} / \mathrm{w}$ hypromellose of solids. The above coating mixture was sprayed on the tablets in a fluididized bed coater (GPCG 1.1, Wurster Insert, Pamm Glatt Pvt, India). The coated tablets were dried in an oven at $60^{\circ} \mathrm{C}$ for $12 \mathrm{~h}$.

\section{Effervescent layer coating}

An effervescent agent sodium bicarbonate was incorporated into HPMC solution plasticized with 
PEG $6000(10 \%$, w/w based on the solids content of HPMC) and then layered onto the coated tablets. On a dry solid basis, the ratios of sodium bicarbonate to HPMC were 2:8, 5:5 and $8: 2 \mathrm{w} / \mathrm{w}$. The coating level of effervescent layer was $12 \%$ weight gain and the solid content of the coating solution was kept constant at $12 \% \mathrm{w} / \mathrm{w}$.

The coating solution was sprayed onto the core tablets using a fluidized bed coater. The conditions for layering were as follows: bead charge, $300 \mathrm{~g}$; preheating temperature, $50^{\circ} \mathrm{C}$; preheating time, $20 \mathrm{~min}$; inlet temperature, $50^{\circ} \mathrm{C}$; outlet temperature, $40-42^{\circ} \mathrm{C}$; atomizing air pressure, $25 \mathrm{lb} / \mathrm{in} 2$; spray rate, $8-10 \mathrm{ml} / \mathrm{min}$. The $\mathrm{NaHCO}_{3}$-layered tablets were dried in the coating chamber for $30 \mathrm{~min}$ at $50^{\circ} \mathrm{C}$ to evaporate the residual moisture. The prepared tablets were then removed from the coating chamber and stored in a closed container for further experiments. The $\mathrm{NaHCO}_{3}$-layered tablets were subsequently coated with an aqueous colloidal polymethacrylate dispersion (Eudragit $\circledast \mathrm{RL} 30 \mathrm{D}$, RS $30 D$,) to achieve a weight gain of 5 and $10 \%$ $\mathrm{w} / \mathrm{w}$ to obtain the complete multiple-unit floating drug delivery system (FDDS).

\section{Polymeric layer coating}

A plasticizer Diethyl phthalate $(20 \%$, w/w based on polymer solids) was added into the colloidal polymer dispersions (Eudragit $\circledast$ RL $30 \mathrm{D}$ and Eudragit RS 30D) and the dispersions were gently agitated for at least $30 \mathrm{~min}$ prior to an appropriate dilution with purified water and subsequent coating. Eudragit@ NE 30D can form film without the need of a plasticizer and thus diluted with water without the incorporation of a plasticizer. The solids content of the coating dispersions was $15 \% \quad \mathrm{w} / \mathrm{w}$. The coating conditions were as follows: bead charge, $300 \mathrm{~g}$; preheating temperature, $45^{\circ} \mathrm{C}$; preheating time, $20 \mathrm{~min}$; inlet temperature, $45^{\circ} \mathrm{C}$; outlet temperature, $40-42^{\circ} \mathrm{C}$; atomizing air pressure, $25 \mathrm{lb} / \mathrm{in}^{2}$; spray rate, $3-5 \mathrm{ml} / \mathrm{min}$. The tablets were further dried in the coating chamber for 60 min after the coating was finished in order to evaporate the residual moisture in the polymeric coatings prior to storage. The dried tablets were filled into capsules and analysed.

\section{Evaluation of core and multiple-unit FDDS}

The core and coated mini tablets were evaluated for the following pharmacopoeia tests: Friability, floating behaviour, content uniformity, in vitro dissolution, in vivo $\mathrm{x}$ ray studies (Konica Minolta,
Siemens, Karlsruhe, Germany), and stability studies.

\section{Differential scanning calorimetry}

For drug-excipient interaction study, a differential scanning calorimeter (DSC 823e, Mettler Toledo) was used. Individual samples (drug and excipients) as well as mixtures of drug and selected excipients were taken in the pierced DSC aluminum pan and scanned in the temperature range of $80-250^{\circ} \mathrm{C}$ (at a heating rate of $5^{\circ} \mathrm{C} \mathrm{min}^{-1}$ ) under an atmosphere of dry nitrogen.

\section{Friability}

The friability of the core mini tablets were determined as the percentage of weight loss after 100 revolutions of $10 \mathrm{~g}$ of the core mini tablets in a friability test apparatus (Electrolab; Model EF-2 Friabilator) (USP).

\section{Floating behavior}

The floating abilities of the effervescent-layered units and the coated effervescent-layered units (complete multiple unit FDDS) were determined using USP II apparatus (50 rpm, $37 \pm 0.5^{\circ} \mathrm{C}, 900$ $\mathrm{ml}, 0.1 \mathrm{~N} \mathrm{HCl}$ ). Units were placed in the medium; the time required to float was measured by visual observation.

\section{Content uniformity}

Twenty capsules were emptied into a mortar after weighing while the tablets were crushed to fine powder. Accurately weighed powders equivalent to $200 \mathrm{mg}$ of quetiapine were transferred from the mortars into a clean dry 250 $\mathrm{ml}$ volumetric flask. About $240 \mathrm{ml}$ of methanol $(1000 \mathrm{ml})$ containing $8.8 \mathrm{ml} \mathrm{HCl}(35 \%)$ used as a diluent was added, and sonication was carried out for $15 \mathrm{~min}$. The flask was shaken for $5 \mathrm{~min}$ and made up to volume with more diluents. The sample was filtered through $0.45 \mu \mathrm{m}$, membrane filter and the first $5 \mathrm{ml}$ was discarded. Buffer was used to dilute $5 \mathrm{ml}$ to $50 \mathrm{ml}$ and content uniformity of samples was determined by high performance liquid chromatography (HPLC).

\section{In vitro dissolution}

The Quetiapine release from different formulations was determined using a USP apparatus 1. The dissolution medium was $900 \mathrm{ml}$ $\left(\mathrm{pH} 1.2\right.$, no enzyme) at $37 \pm 0.5^{\circ} \mathrm{C}$; one capsule was placed in each dissolution vessel and the 
basket speed was set at $100 \mathrm{rpm}$. All experiments were done in triplicate and average values were taken. The formulation prepared was subjected to dissolution tests for $12 \mathrm{~h}$. Samples $(5 \mathrm{ml})$ were withdrawn at predetermined time intervals, filtered through filter paper $(0.45$ $\mu \mathrm{m}$ ) and replaced by an equal volume of fresh dissolution medium. Drug content in the dissolution sample was determined by HPLC.

\section{HPLC analysis}

Quantitative determination of Quetiapine was performed by HPLC. A waters alliance HPLC system with quarternary-2699 pump with 2489 UV-Vis detector, and X-Terra C18 $(150 \times 4.6 \mathrm{~mm}$ ID., particle size $5 \mu \mathrm{m}$ ) was used. The HPLC system was equipped with the Empower software. New method was developed for quantitation of quetiapine. The mobile phase consisted of mixture of buffer and acetonitrile (400:600). The filtered mobile phase was pumped at a flow rate of $1.5 \mathrm{ml} \mathrm{min}{ }^{-1}$. Ten microliters of sample was injected into the column and the retention time of Quetiapine was found to be $3.5 \mathrm{~min}$. The eluent was detected by UV at $292 \mathrm{~nm}$. The drug release was calculated using the equation generated from standard curve. The percentage cumulative drug release was calculated.

\section{Kinetic modeling of drug release}

The suitability of several equations, which are reported in the literature to identify the order and mechanism for the release of drug, was tested with respect to the release data. The data for analysis was taken to Q8 (drug released up to 8 h) excluding the lag time for all models except (Korsmeyer-Peppas) model. Peppas diffusion model is expected to be valid only up to approximately $60 \%$ cumulative drug released. Thus FDDS with up to $60 \%$ cumulative drug release was considered. The data were evaluated as Eqs 1 - 4 .

$$
\text { Zero-order: } Q_{t}=Q_{0}+k_{0} t \ldots \ldots \ldots \ldots \ldots \ldots \ldots(1)
$$

where, $Q_{t}$ is the amount of drug release in time $t$, $Q_{0}$ is the initial amount of drug in the solution (most times, $Q_{0}=0$ ) and $k_{0}$ is the zero-order release rate.

First-order: In $Q_{t}=\ln Q_{0}=k_{1} t$

where, $Q_{t}$ is the amount of drug released in time $t, Q_{0}$ is the initial amount of drug in the solution and $k_{1}$ is the first-order release rate constant.
Higuchi: $Q=k_{H} t^{1 / 2}$

where, $Q$ is the amount of drug release at time $t$, and $\mathrm{k}_{\mathrm{H}}$ is the Higuchi diffusion rate constant

Koresmeyer: $M_{t} / M_{\infty}=k t^{n}$

where, $M_{t}$ is the amount of drug released at time $t, M_{\infty}$ is the amount of drug released after infinite time, $\mathrm{k}$ is a kinetic constant incorporating structural and geometric characteristics of the tablet, and $\mathrm{n}$ is the diffusional exponent indicative of the drug release mechanism.

\section{In vivo x-ray studies}

The in vivo tests were performed on six healthy male volunteers whose age was between 25 and 32 years and weighted between 60 and $71 \mathrm{~kg}$ (approval for the study was obtained from the University Ethical Committee, UCPSc, Kakatiya University, Warangal, AP, India); $20 \%$ of $\mathrm{BaSO}_{4}$ was used to replace the drug in the final formulation (the amount of $\mathrm{BaSO}_{4}$ that allowed visibility by X-ray, but does not preclude the floating of tablets, was experimentally determined). Labeled floating multiple unit dosage form (placebo) was given to subjects with $250 \mathrm{ml}$ of water after a light, 308 kcal breakfast. Following ingestion, gastric radiography was undertaken at $0.5,1,3,4$ and $6 \mathrm{~h}$, and the duration of the mini-tablets stay in the stomach was recorded.

\section{Stability studies}

To assess the drug and formulation stability, stability studies were done according to $\mathrm{ICH}$ and WHO guidelines $[7,9]$. Optimized formulation was kept in the humidity chamber (Lab Top, India) maintained at $40^{\circ} \mathrm{C}$ and $75 \%$ Relative Humidity for 6 months. At the end of studies, samples were analyzed for physicochemical parameters. For the comparison of release profiles of initial and stability samples, "difference factor" f1 and "similarity factor" f2, were calculated [10]. The difference factor (f1) measures the percent error between the two curves over all time points and was calculated. The two release profiles are considered to be similar, if $\mathrm{f} 1$ value is lower than 15 (between 0 and 15). The similarity factor (f2) is a logarithmic transformation of the sum of squared error of differences between the test $\mathrm{Tj}$ and the reference products $\mathrm{Rj}$ over all time points. The two dissolution profiles are considered to be similar, if $\mathrm{f} 2$ value is greater than 50 . 


\section{Statistical analysis}

Comparison among the developed formulations and reference formulations was carried out by student-t test and one way ANOVA to determine statistical difference between sets of data. All the tests were run in triplicate $(n=3)$. Quantitative data were expressed as mean \pm standard deviation (SD). Statistically significant difference between formulations set at $p \leq 0.05$ was used to compare the drug release data. The software used was SigmaPlot 11 (Systat Software Inc).

\section{RESULTS}

Before compression of core tablets the flow properties were measured. The final blend of all the batches showed good flowability (angle of repose $<30^{\circ}$ ) and having the Bulk density was $0.414 \mathrm{~g} / \mathrm{cm} 3$. Tapped density was $0.606 \mathrm{~g} / \mathrm{cm} 3$, compressibility $31.579 \%$, and Hausner ratio 1.461.

\section{Characteristics of mini-tablets}

All the physical parameters evaluated for quality control were within the acceptable limits of the Pharmacopoeia. Friability of the formulation was $0.4 \pm 0.08 \%$. This indicated that the core units were quite hard and able to withstand the mechanical stresses of the subsequent coating process.

\section{Thermal properties}

The DSC thermogram of the pure drug, excipients, physical mixture of drug and polymer which was kept at $40 \pm 2^{\circ} \mathrm{C}$ and $75 \pm 5 \% \mathrm{RH}$ were taken and endothermic peak of melting of drug appeared at $172-174^{\circ} \mathrm{C}$ indicating that there was no incompatibility between drug, excipients, physical mixture of drug and polymer.

\section{Buoyancy and drug release profiles}

Mini tablets Coated with Eudragit RS $30 \mathrm{D}(5,7.5$ and $10 \%$ ) released $\leq 85 \%$ of the drug after $12 \mathrm{~h}$, while those coated with Eudragit RL $30 \mathrm{D}(5,7.5$ and $10 \%$ ) released $\geq 85 \%$ drug within the same period. Mini tablets coated with combination Ratios of Eudragit RL 30D and Eudragit RS 30D $(1: 3,3: 1$ and 1:1) did not show good floating properties but when Eudragit RL 30D was also coated at same coating levels and effervescent agent (sodium bicarbonate) at ratios of polymer and effervescent agent $(1: 3)$ and $10 \%$ coating levels, the formulation showed good floating behaviour and suitable drug release patterns were produced.

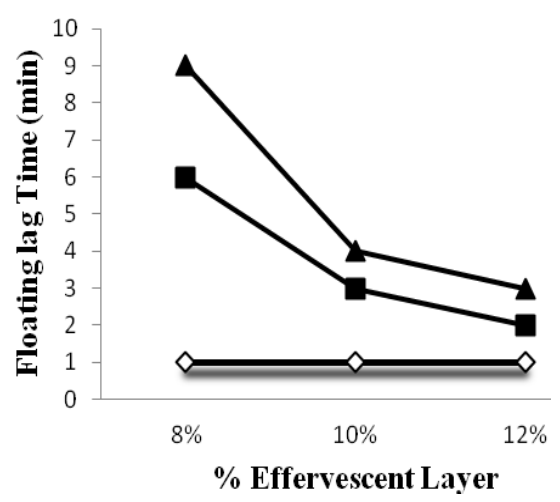

Figure 1: Effect of effervescent layer level on floating lag time. Key: Eudragit RL 10\%, ( $\mathbf{\Lambda}$ ); Eudragit RL 5\%, (-); Eudragit RL 0\% (仓)

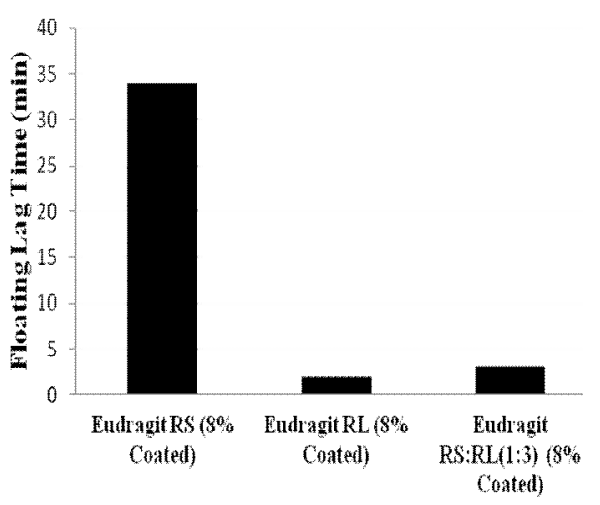

Polvmeric Coatings

Figure 2: Effect of polymer coating on floating lag time at $10 \%$ effervescent coating level

\section{DISCUSSION}

The floating ability of the effervescent-layered units and the effervescent-layered units coated with polymeric membrane were investigated with respect to amount of the effervescent agent coated and type and level of the polymeric coating. The system should float within a few minutes after contact with gastric fluid to prevent the dosage form from transiting into the small intestine together with food. The percent coating level of effervescent layer was evaluated and of minimum was found to be $10-12 \%$ for floating. The effervescent layered units floated within 5 $10 \mathrm{~s}$ after placing in $0.1 \mathrm{~N} \mathrm{HCl}$. The floating time of the effervescent-layered units was short $(<3$ h) because HPMC dissolved and there was no polymeric membrane to entrap the generated $\mathrm{CO}_{2}$ gas. Therefore, the complete multiple-unit FDDS (effervescent layered units coated with polymeric membrane) were prepared and evaluated for floating ability.

Cellulose acetate was too rigid and did not expand sufficiently when in contact with 

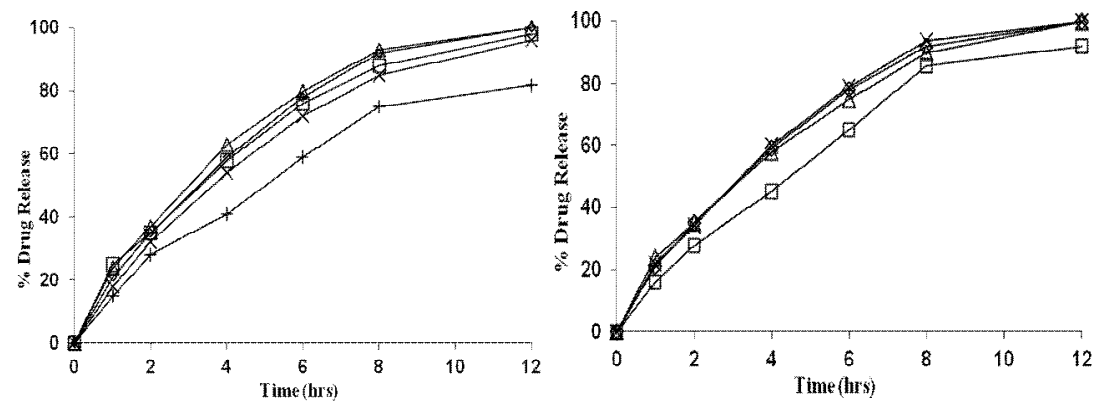

Figure 3: Comparative dissolution profiles of Quetiapine fumarate mini tablets in $0.1 \mathrm{~N} \mathrm{HCl}$ with different level of polymeric coating and their combinations. a: $(\diamond=$ Marketed product; $\Delta=$ Eudragit $\mathrm{RL} 5 \%$; $\square=$ Eudragit $\mathrm{RL} 8 \% ; \mathrm{x}=$ Eudragit RL 10\%; + = Eudragit RS $8 \%)$. b: $(\diamond=$ Marketed product; $\Delta=$ ERL: ERS $(1: 1,8 \%)$; $\square=$ ERL: ERS $(1: 3$, $8 \%) ; x=E R L:$ ERS $(3: 1,8 \%)$.

$0.5 \mathrm{hr}$
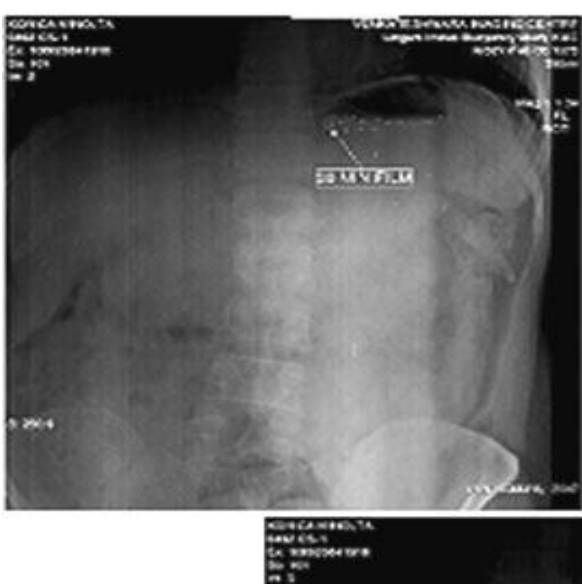

急
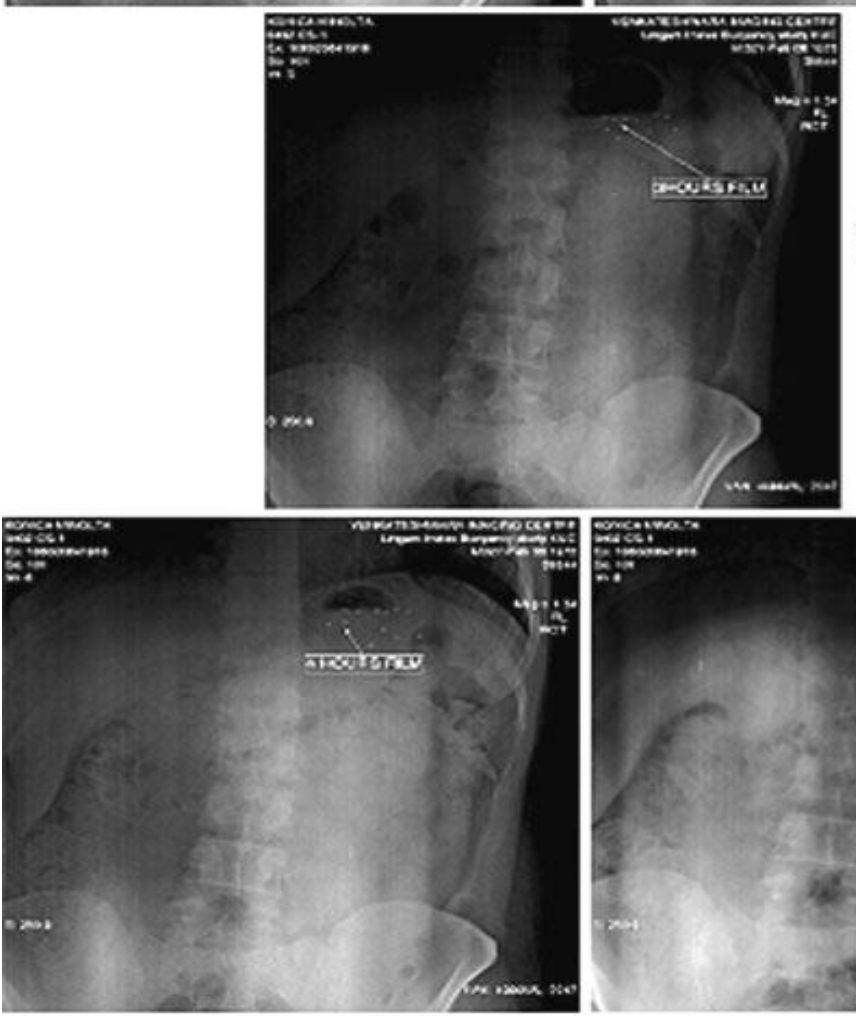

$4 \mathrm{hr}$
$1 \mathrm{hr}$

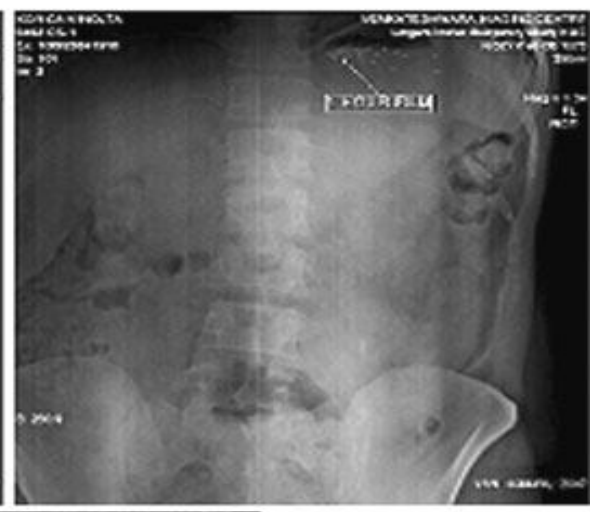

$3 \mathrm{hr}$

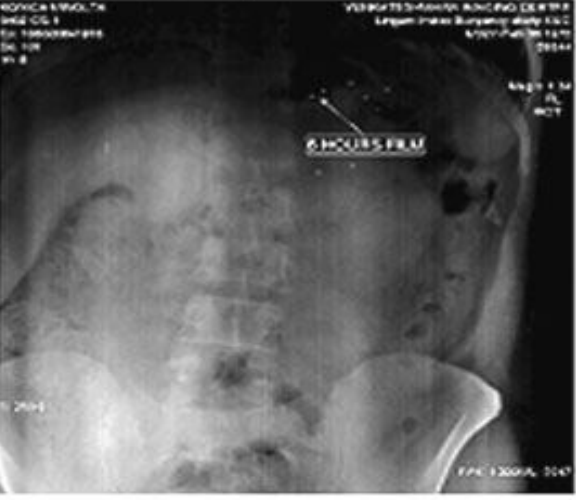

$6 \mathrm{hr}$

Figure 4: In-vivo gastric residence time of floating mini-tablets obtained using x-ray studies 
dissolution media, while ethyl cellulose was not flexible and ruptured easily upon $\mathrm{CO}_{2}$ formation. Gas bubbles were released rapidly after the burst of coating. Hence, the higher flexibility of the polymethacrylate polymers (Eudragit RS 30D, RL 30D, and RS 30D: RL 30D). Upon contact with the gastric fluid, the fluid permeated into the effervescent layer through the outer polymeric membrane. Carbon dioxide was liberated via neutralization reaction and was entrapped in the polymeric membrane. After that, the swollen mini tablets with a density less than $1.0 \mathrm{~g} / \mathrm{ml}$ floated and maintained the buoyancy; therefore, the drug was released from the system for a long time.

The multiple-unit FDDS using Eudragit RL 30D and Eudragit RS: RL 30D as polymeric membranes floated completely within $3 \mathrm{~min}$. The time to float of the systems decreased with increasing amount of effervescent agent and increased with increasing level of polymeric membrane coating. The higher amount of effervescent agent caused faster and higher $\mathrm{CO}_{2}$ generation [10]. With increasing level of Eudragit $\mathrm{RL} 30 \mathrm{D}$, the floating was delayed due to slow water penetration through the thicker coating. The duration of floating was longer than $8 \mathrm{~h}$. It was found that Eudragit RL $30 \mathrm{D}$ and RS: RL combinations was impermeable to the generated $\mathrm{CO}_{2}$ and could maintain the floatation. The multiple-unit FDDS systems coated with Eudragit RS $30 \mathrm{D}$ as polymeric membranes did not float within 20 min even when used with high effervescent coating level $(15 \% \mathrm{w} / \mathrm{w}$ weight gain).The time to float decreased as amount of the effervescent agent increased and coating level of gas-entrapped polymeric membrane decreased. The optimum system could float completely within $3 \mathrm{~min}$ and maintained the buoyancy over a period of $12 \mathrm{~h}$ (Figure 1 and 2 ).

Increasing coating level of gas-entrapped polymeric membrane decreased the drug release. Combination of Eudragit $\mathrm{RL}$ and Eudragit RS with $8 \%$ coating level with different ratios shows less release than individual Eudragit RL 8\% coating level.

The magnitude of the exponent ' $n$ ' indicates the release mechanism as Fickian diffusion, as in case II transport or as anomalous transport. In the present study (cylindrical shape) the limits considered were $\mathrm{n}=0.45$ (classical Fickian diffusion-controlled drug release) and $n=0.89$ (case II relaxational release transport: polymer relaxation controls drug delivery). Values of $n$ between 0.45 and 0.89 can be regarded as an indicator of both phenomena (transport corresponding to coupled drug diffusion in the hydrated matrix and polymer relaxation) commonly called anomalous non-Fickian transport. Values of $n>0.89$ indicate a super case II transport, in which a pronounced acceleration in solute release by a film occurs toward the latter stages of release experiments, resulting in a more rapid relaxation-controlled transport [8].

The correlation coefficient $\left(R^{2}\right)$ was used as indicator of the best fitting, for the models considered. The results reveal that all formulations of FDDS were best fitted in the zero order and Higuchi model. The mechanism of drug release from these tablets was found to be diffusion controlled as seen from $R^{2}$ values of Higuchi model. The $\mathrm{n}$ values for these systems (ranging between $0.45-0.89$ ), indicates both phenomena (transport corresponding to coupled drug diffusion in hydrated matrix and polymer relaxation) commonly called anomalous nonFickian transport. Drug release was sustained and linear with the square root of time.

Both the rapid floating and the sustained release properties were achieved in the multiple-unit floating drug delivery system developed in this present study. Only the system using Eudragit $(\Omega$ $\mathrm{RL} 30 \mathrm{D}$ as a gas-entrapped polymeric membrane floated.

The in vivo gastric residence time in the stomach was about $6 \mathrm{~h}$. Analysis of the parameter dissolution data after storage at $40^{\circ} \mathrm{C}$ and $75 \%$ $\mathrm{RH}$ for 6 months showed, no significant change indicating the two dissolution profiles were considered to be similar (f2 value was initial-83 and ACC 6M-87, more than 50).

\section{CONCLUSION}

The multiple-unit FDDS based on gas formation technique has been successfully developed. The floating ability and drug release of the system were dependent on amount of the effervescent agent layered onto the core tablets, type and coating level of the polymeric membrane. Only the system using Eudragit ${ }^{\circ} \mathrm{RL} 30 \mathrm{D}$ as a polymeric membrane floated due to the fact that Eudragit@ RL 30D has high water- and low $\mathrm{CO}_{2^{-}}$ permeabilities with high flexibility. The system could float completely within 3 min and maintain the buoyancy over a period of $24 \mathrm{~h}$. The multipleunit FDDS with rapid floating and sustained drug release was obtained and could be a promising gastroretentive DDS. 


\section{ACKNOWLEDGEMENT}

The authors acknowledge University College of Pharmaceutical Sciences, Kakatiya University, Warangal-506009 (A.P), India for their invaluable support during this work. One of the authors (K. Vinay Kumar) is also grateful to AET Laboratories Pvt Ltd (Hyderabad, India) for providing quetiapine fumarate and the facilities for the preparation and coating of mini-tablets.

\section{REFERENCES}

1. Acikgoz M, Kas HS, Hascelik Z, Milli U, Hincal AA. Chitosan microspheres of diclofenac sodium, II: in vitro and in vivo evaluation. Pharmazie. 1995; 50: 275-277.

2. Iannuccelli V, Coppi G, Bernabei MT, Cameroni R. Air compartment multiple-unit system for prolonged gastric residence. Part I. Formulation study. Int $\mathrm{J}$ Pharm. 1998; 174: 47-54.

3. Barbee JG, Conrad EJ, Jamhour NJ. The Effectiveness of Olanzapine, Risperidone, Quetiapine and Ziprasidone as Augmentation Agents in TreatmentResistant Unipolar Depression. J. Clinical Psychiatry. 2004; 65: 975-981.
4. Gao K, Muzina D, Gajwani P, Calabrese JR. Efficacy of typical and atypical antipsychotics for primary and comorbid anxiety symptoms or disorders: a review. J. Clinical Psychiatry. 2006; 67: 1327-1340.

5. Shea S, Turgay A, Carroll A, Schulz M, Orlik H, Smith I. Resperidone in the treatment of disruptive behavioral symptoms in children with autistic and other pervasive developmental disorders. Pediatrics. 2004; 114(5): 634-641.

6. Basak SC, Rahman J. Ramalingam M. Design and in vitro testing of a floatable gastroretentive tablet of metformin hydrochloride. Pharmazie. 62(2); 2007: 145- 148.

7. Ritger PL, Peppas NA. A simple equation for description of solute release. I. Fickian and non-Fickian release from nonswellable devices in the form of slabs, spheres, cylinders or discs. J. Contr. Release. 1987; 5: 23-36.

8. C. H. M. Jacques, H. B. Hopfenberg, V. Stannett. Super case II transport of organic vapors in glassy polymers. In: Hopfenberger HB (ed.), Permeability of Plastic Films and Coatings to Gases, Vapors, and Liquids, Plenum, New York, 1974, pp 73-86.

9. B. R. Mathews. Regulatory aspects of stability testing in Europe. Drug Dev. Ind. Pharm. 1999; 25: 831-856.

10. J. W. Moore and H. H. Flanner. Mathematical comparison of curves with an emphasis on in-vitro dissolution profiles. Pharm. Technol. 1996; 20: 64-74. 